\title{
Experimental Models of Acute and Chronic Sialoadenitis in the Guinea Pig
}

\author{
Katsuhiko Miyazawa, Takashi Mikami, Katsuhiko Miyasaka and Shigeru Aonuma ${ }^{1}$ \\ Pharmacological Research Department, Teikoku Hormone Mfg. Co., Ltd., I604 Shimosakunobe, Takatsu-ku, Kawasaki 213, Japan \\ ${ }^{\prime}$ Faculty of Pharmaceutical Science, Kinki University, Higashiosaka 577, Japan \\ Received January 29, 1992 Accepted May 9, 1992
}

\begin{abstract}
Acute and chronic sialoadenitis were induced in ovalbumin-immunized guinea pigs by a single or repeated (once a day for 5 days) instillation of antigen into the parotid gland via the parotid duct. The acute sialoadenitis was characterized by infiltration of inflammatory polymorphonuclear leukocytes and the chronic one, by extensive tissue destruction together with infiltration of mononuclear leukocytes. In acute sialoadenitis, myeloperoxidase activity in the parotid gland, which was a marker of accumulation of neutrophils, was elevated, but in the chronic stage, it returned nearly to the control level. This observation is in accord with the histological findings that infiltrating cells in acute and chronic sialoadenitis were mainly polymorphonuclear and mononuclear leukocytes, respectively. Although cyclophosphamide suppressed the inflammation, both in acute and chronic sialoadenitis, indomethacin exerted its anti-inflammatory effect only in the acute stage. Our experimental models of acute and chronic sialoadenitis were easy to prepare, and had a high incidence. As the typical features of inflammatory development from acute to chronic phases were observed in these models, these models may be useful for studying the mechanism of the chronic course in immunologically induced inflammation and the effects of drugs on each phase and the chronic course of inflammation.
\end{abstract}

Keywords: Sialoadenitis, Inflammation, Parotid gland, Leukocyte, Myeloperoxidase activity

Experimental allergic sialoadenitis has been investigated to explain the pathogenesis of certain inflammatory processes of the salivary glands such as Sjögren's disease. Although several models of experimental sialoadenitis induced by various immunological methods in rats have been reported by a group of authors in Israel $(1-8)$, the lack of chemotactic activity of leukotriene $\mathrm{B}_{4}\left(\mathrm{LTB}_{4}\right)$ for the rat neutrophil raises questions about the usefulness of rats in the screening of anti-inflammatory agents for potential use in the treatment of human disease (9). In this report, we showed easy methods for inducing both acute and chronic experimental allergic sialoadenitis in guinea pigs with a high incidence. We also described pathological characteristics of each phase of sialoadenitis, and the effects of drugs (indomethacin and cyclophosphamide) on them.

\section{MATERIALS AND METHODS}

\section{Sensitization of animals}

Sensitization of animals was carried out as described by Orange and Moore (10). Male Hartley strain guinea pigs (5 weeks old, SPF, Japan SLC, Inc.) were immunized by intraperitoneal injection with ovalbumin (1 $\mathrm{mg}$ /animal) emulsified with an equal volume of complete Freund's adjuvant and boosted 3 to 4 weeks later by intradermal injection of ovalbumin ( $100 \mu \mathrm{g} \times 4$ points). One week after the booster dose, an aliquot of blood was collected and the antibody titer to ovalbumin was assayed by a test for homologous passive cutaneous anaphylaxis (PCA). The PCA test was considered positive when a spot of dye leakage, $5 \mathrm{~mm}$ or more in diameter, developed. Animals, whose sera were eliciting positive 4-hr PCA responses at a dilution of 1:4000, were used for this study. 


\section{Induction of acute and chronic sialoadenitis}

Intraductal instillation of antigen into the parotid gland was performed by the method described by Ulmansky et al. (8). Animals were anesthetized with ether and placed on their backs, the mouth was opened by traction with rubber bands and sterilized with $70 \%$ ethanol. The orifices of the parotid ducts were identified behind the hillocks of the inner cheeks. A small knot with silk thread was made at the top of the hillock of the right inner cheek. The orifice of the right parotid duct was easily observed by pulling the knot gently with a Kocher's forceps. A polyethylene catheter (SP45) with its guiding stainless steel stylet $(0.5 \mathrm{~mm}$ in diameter) was introduced into the duct to a depth of approximately $2 \mathrm{~cm}$. The stylet was retrieved and $0.5 \mathrm{ml}$ of ovalbumin solution $(10 \mathrm{mg} / \mathrm{ml}$ in the acute model, 2 $\mathrm{mg} / \mathrm{ml}$ in the chronic model) or saline was slowly injected without undue pressure. A single challenge was done in the acute sialoadenitis model and daily challenges for consecutive 5 days were performed in the chronic model. At $24 \mathrm{hr}$ after the (last) challenge, except in the time-course study, the animals were anesthetized with urethane $(1.5 \mathrm{~g} / \mathrm{kg})$ and $0.01 \%$ Evans blue solution was injected into the parotid gland to distinguish it from surrounding tissues easily. Blood was drawn by heart puncture. A portion of the gland was fixed in buffered formalin, and another portion of the gland was frozen and storcd at $-70^{\circ} \mathrm{C}$ until the extraction of myeloperoxidase.

\section{Histological study}

The parotid glands fixed in buffered formalin were embedded in paraffin. Five-micron sections were prepared and stained with hematoxylin and eosin. The histological findings in the parotid glands with respect to (a) cell infiltration and (b) tissue destruction were evaluated according to criteria and scored semiquantitatively on the following arbitrary scale of 0 to $4+$ : (a) Scoring in cell infiltration: score 0 , glands showing no inflammatory cell infiltration; score $1+$, a few inflammatory cells infiltrating into the interlobular connective tissues; score $2+$, numerous cells infiltrating into the interlobular and intralobular connective tissues; score $3+$, more numerous cells infiltrating into the interlobular and intralobular connective tissues and some invading the acini and the ductal epithelium; score 4, highly extensive inflammatory cell infiltration, with all fields filled with inflammatory cells. (b) Scoring in tissue destruction: scoring was made corresponding to the degree of loss of acini from 0 (no loss of acini) to 4+ (nearly complete loss of acini). Histological observation was done in ten fields, and the modal score was determined in each preparation.
Myeloperoxidase assay

Myeloperoxidase (MPO) was extracted from the homogenized tissues by suspending the material in $0.5 \%$ hexadecyltrimethylammonium bromide in $50 \mathrm{mM}$ phosphate buffer, $\mathrm{pH} \mathrm{6.0,} \mathrm{before} \mathrm{sonication} \mathrm{in} \mathrm{an} \mathrm{ice}$ bath for $10 \mathrm{sec}$. The specimens were freeze-thawed 3 times, after which sonication was repeated (11). An aliquot of suspension was collected and dissolved in $1 \mathrm{~N}$ $\mathrm{NaOH}$ solution, and the protein content was measured with a protein assay kit (Bio-Rad, USA) for correction of enzyme activity. The residual suspension was centrifuged $(2,000 \times \mathrm{g}, 10 \mathrm{~min})$ and filtered through a membrane filter.

MPO activity was assayed spectrophotometrically: an aliquot of the sample (up to $100 \mu$ ) to be measured was mixed with $2.9 \mathrm{ml}$ of $50 \mathrm{mM}$ phosphate buffer, $\mathrm{pH}$ 6.0 , containing $5 \% \mathrm{~N}, \mathrm{~N}$-dimethylformamide. Then $50 \mu \mathrm{l}$ of $3.6 \mathrm{mg} / \mathrm{ml}$ of $3,3,5,5$ 'tetramethylbenzidine dihydrochloride and $100 \mu \mathrm{l}$ of $0.052 \%$ hydrogen peroxide were added. The change in absorbance at $654 \mathrm{~nm}$ was measured with a spectrophotometer with stirring at $25^{\circ} \mathrm{C}$ for 2 min. One unit (U) of MPO activity was defined as that degrading one micromole of peroxide per minute at $25^{\circ} \mathrm{C}$. MPO activity in the parotid glands was shown as $\mathrm{mU} / \mathrm{mg}$ protein of the tissue.

\section{Drug treatment}

Indomethacin (IM) and cyclophosphamide (CP) were prepared as a suspension in $2 \%$ arabic gum and administered intraperitoneally. IM $(10 \mathrm{mg} / \mathrm{kg})$ was administered at $24 \mathrm{hr}$ and $1 \mathrm{hr}$ before and $6 \mathrm{hr}$ after the antigen challenge in the acute model and at $24 \mathrm{hr}$ before the first antigen challenge and $1 \mathrm{hr}$ before each antigen challenge in the chronic model. Daily administration of $\mathrm{CP}(20 \mathrm{mg} / \mathrm{kg})$ was started from 5 days before the challenge in each model.

\section{Chemicals}

The main chemicals used in the experiments were as follows: ovalbumin grade V (Sigma, USA), indomethacin (Wako, Japan), complete Freund's adjuvant, cyclophosphamide, 3,3,5,5'-tetramethylbenzidine dihydrochloride (Nacalai Tesque, Japan).

\section{RESULTS}

Sialoadenitis was induced by antigen instillation into the parotid gland and the incidence rate was practically $100 \%$ both in the acute and chronic models $(15 / 15$ and $17 / 17$, respectively), when using animals with a consistent PCA reaction at least to $1: 4000$ antigen dilution. The great majority of the animals immunized by the procedure described full-filled this criterion (193/206 in 
our current study).

\section{Acute sialoadenitis}

Time course of histological findings and MPO activity in the parotid glands are shown in Table 1 and Fig. 1, respectively, in the acute sialoadenitis induced by a single challenge of ovalbumin. Cell infiltration was hardly observed in the intact parotid glands as shown in Fig. 2a. Mild infiltration of the cells into the interlobular connective tissues was observed at $2 \mathrm{hr}$ after the challenge, and the infiltration was increased significantly with time. At $4 \mathrm{hr}$ after, cell infiltration was observed also in the intralobular connective tissues; and together with more severe infiltration, partial loss of acini was observed in some lobules at $24 \mathrm{hr}$ after the challenge

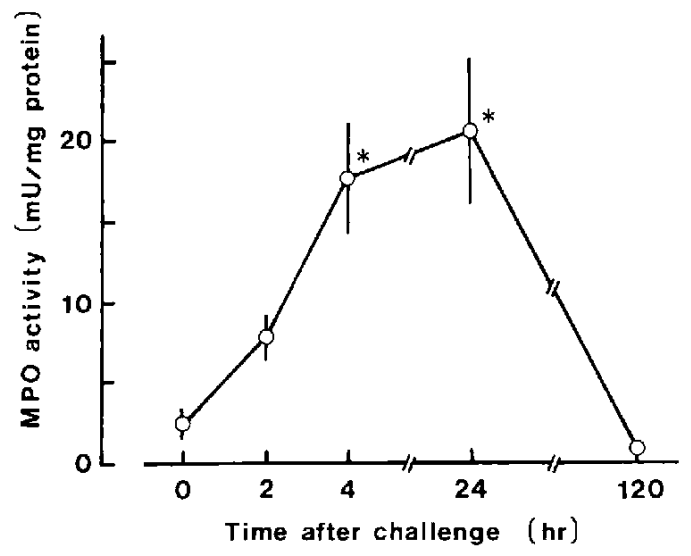

Fig. 1. A time-course study of myeloperoxidase activity in the parotid gland of animals with sialoadenitis after a single intraductal challenge of antigen. Each value represents the mean \pm S.E. of $8,8,8,6$ and 4 animals at $0,2,4,24$ and $120 \mathrm{hr}$, respectively. ${ }^{*} \mathbf{P}<0.05$, significantly different from the initial $(0 \mathrm{hr})$ value (Dunnett's test).
(Fig. 2b). Although infiltrating cells in the tissues and a partial loss of acini which was observed at $24 \mathrm{hr}$ after the challenge still existed, further loss of acini such as that observed in the chronic model was not observed at $120 \mathrm{hr}$ after the challenge. Although MPO activity in the tissue, which was an index of neutrophil infiltration, was increased parallel to the cell infiltration until at 24 hr after the challenge ( $r=0.83$ by Spearman's correlation coefficient, $n=30$ ), the activity was restored to its control level by $120 \mathrm{hr}$ after the challenge. These findings were in accord with the histological observations showing that the main infiltrating cells at $120 \mathrm{hr}$ after the challenge were not polymorphonuclear leukocytes but mononuclear leukocytes. In the acute model, the main characteristic was inflammatory cell infiltration rather than tissue destruction such as loss of acini.

\section{Chronic sialoadenitis}

In the chronic sialoadenitis caused by consecutive challenges of antigen, apparent histological changes were observed (Fig. 2c, Table 2). Parenchymal atrophy, ectasia of the intralobular ductules and marked loss of acini were observed together with severe cell infiltration predominantly consisting of mononuclear leukocytes such as lymphocytes; and moreover, some preparations showed partial formation of fibrillosis. In contrast to acute sialoadenitis, significant increase of MPO activity was not observed in chronic sialoadenitis. Only mild cell infiltration was clicited in some cases treated with consecutive intraductal instillation of saline for 5 days. Similar results were obtained in non-sensitized animals treated with repeated intraductal instillations of antigen (Table 2).

Table 1. Incidence of sialoadenitis following a single intraductal challenge in the time-course study

\begin{tabular}{|c|c|c|c|c|c|c|c|c|c|c|}
\hline \multirow{2}{*}{$\begin{array}{l}\text { Time after } \\
\text { challenge }\end{array}$} & \multirow{2}{*}{0} & \multicolumn{4}{|c|}{$\begin{array}{l}\text { Score of } \\
\text { cell infiltration }\end{array}$} & \multicolumn{5}{|c|}{$\begin{array}{l}\text { Score of } \\
\text { tissue destruction }\end{array}$} \\
\hline & & 1 & 2 & 3 & 4 & 0 & 1 & 2 & 3 & 4 \\
\hline $0 \mathrm{hr}$ & 8 & 0 & 0 & 0 & 0 & 8 & 0 & 0 & 0 & 0 \\
\hline $2 \mathrm{hr}$ & 0 & 6 & 2 & 0 & 0 & 8 & 0 & 0 & 0 & 0 \\
\hline $4 \mathrm{hr}$ & 0 & 0 & 4 & 4 & $0^{* *}$ & 5 & 3 & 0 & 0 & 0 \\
\hline $24 \mathrm{hr}$ & 0 & 0 & 0 & 0 & $8^{* *}$ & 2 & 5 & 1 & 0 & $0^{* *}$ \\
\hline $120 \mathrm{hr}$ & 0 & 0 & 4 & 2 & $0^{* *}$ & 2 & 4 & 0 & 0 & $0^{*}$ \\
\hline
\end{tabular}

Values are the incidences of various degrees of sialoadenitis following a single intraductal challenge. Histological findings for cell infiltration and tissue destruction were evaluated according to the criteria and scored as described in the Methods. ${ }^{*} \mathrm{P}<0.05,{ }^{*} \mathrm{P}<0.01$, significantly different from the initial $(0 \mathrm{hr})$ value (non-parametric Dunnett's type test). 
a)

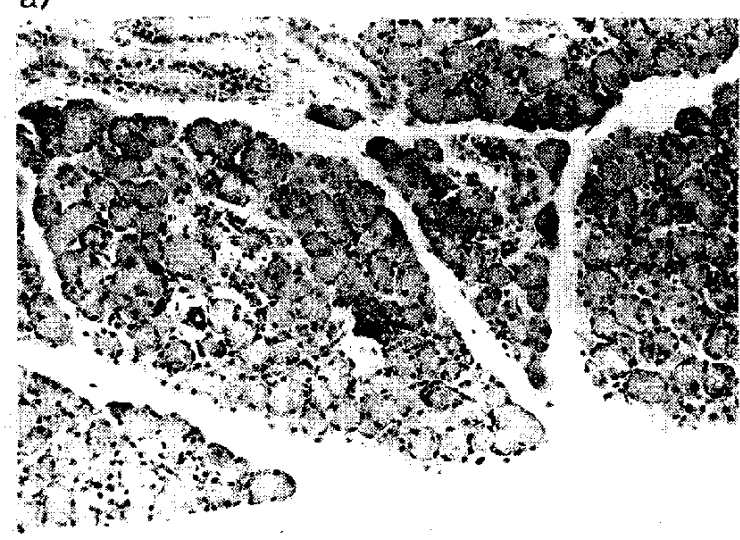

c)

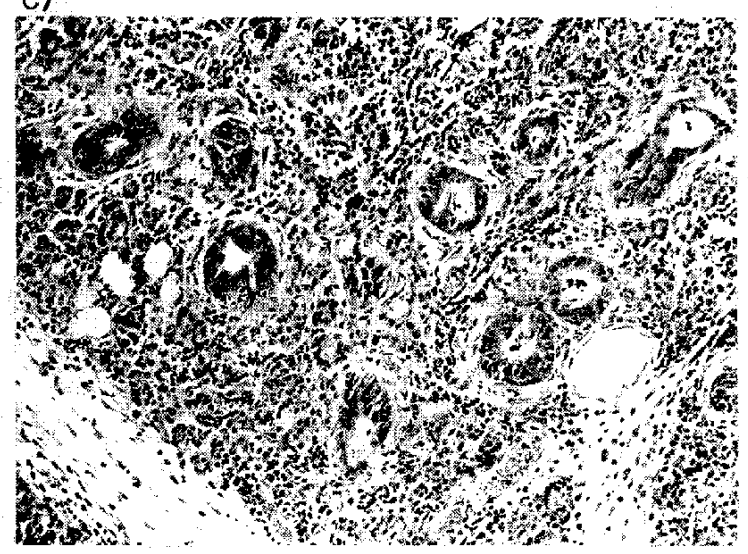

b)

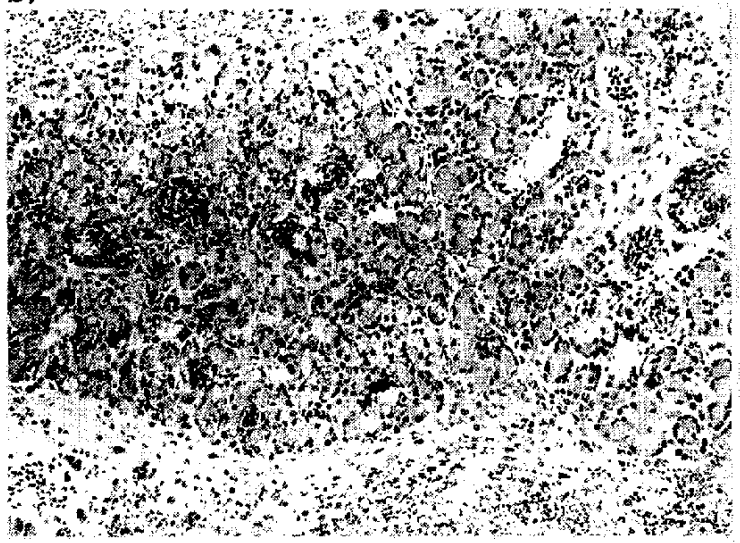

d)

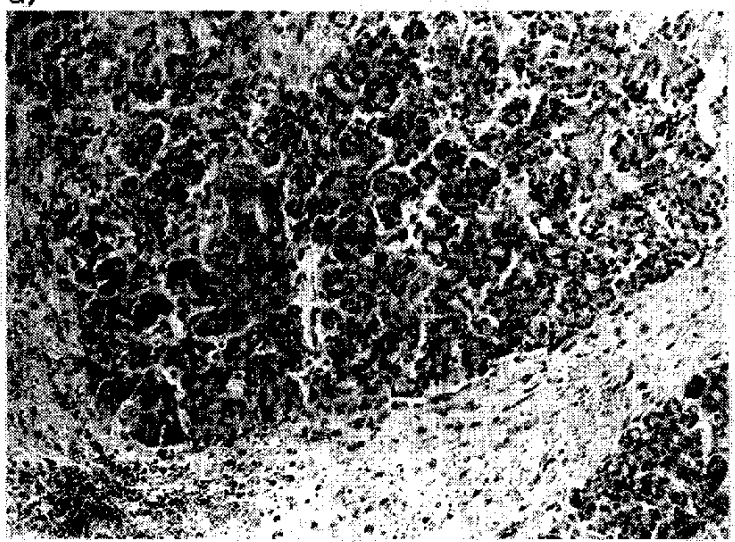

Fig. 2. Typical light micrographs of the parotid gland. a) Intact parotid gland (score: cell infiltration 0 , tissue destruction 0). b) Acute sialoadenitis at $24 \mathrm{hr}$ after a single intraductal challenge of antigen. Predominantly polymorphonuclear cellular infiltration and partial acinar loss are observed (score: cell infiltration 4, tissue destruction 1). c) Chronic sialoadenitis after multiple intraductal challenges of antigen. Predominantly mononuclear cellular infiltration, marked acinar loss and ectasia of the ductules are observed (score: cell infiltration 4, tissuc destruction 4). d) Chronic sialoadenitis treated with cyclophosphamide. Tissue destruction, together with inflammatory cell infiltration, is suppressed by the treatment with cyclophosphamide (score: cell infiltration 3, tissuc destruction 2). Hematoxylin-eosin. Original magnification $\times 50$.

Table 2. Incidence of sialoadenitis following multiple intraductal challenges for 5 days

\begin{tabular}{|c|c|c|c|c|c|c|c|c|c|c|}
\hline & \multicolumn{4}{|c|}{$\begin{array}{l}\text { Score of } \\
\text { cell infiltration }\end{array}$} & \multirow[b]{2}{*}{4} & \multicolumn{4}{|c|}{$\begin{array}{l}\text { Score of } \\
\text { tissue destruction }\end{array}$} & \multirow[b]{2}{*}{4} \\
\hline & 0 & 1 & 2 & 3 & & 0 & 1 & 2 & 3 & \\
\hline $\begin{array}{l}\text { a) Immunized } \\
\text { Challenge: } \mathrm{OA}\end{array}$ & 0 & 0 & 0 & 0 & 7 & 0 & 0 & 1 & 2 & 4 \\
\hline $\begin{array}{l}\text { b) Immunized } \\
\text { Challenge: saline }\end{array}$ & 0 & 2 & 2 & 0 & $0^{* *}$ & 4 & 0 & 0 & 0 & $0^{* *}$ \\
\hline $\begin{array}{l}\text { c) Not immunized } \\
\text { Challenge: OA }\end{array}$ & 1 & 1 & 1 & I & $0^{* *}$ & 3 & 1 & 0 & 0 & $0^{*}$ \\
\hline
\end{tabular}

Values are the incidences of various degrees of sialoadenitis in nomnal (not immunized) and immunized animals following multiple intraductal challenges. Histological findings were evaluated according to the criteria and scored as described in the Methods. OA: ovalbumin. ${ }^{*} \mathrm{P}<0.05,{ }^{*} \mathrm{P}<$ 0.01 , significantly different from the a) group (Mann-Whitney $U$-test). 


\section{Effects of drugs}

Effects of drugs on acute sialoadenitis estimated at 24 hr after a single challenge are shown in Table $3 \mathrm{a}$ and Fig. 3a. IM $(10 \mathrm{mg} / \mathrm{kg})$ suppressed both cell infiltration and the increase of tissue MPO activity. CP $(20 \mathrm{mg} / \mathrm{kg}$ $\times 5$ preceding days) also suppressed both of them. In addition, consecutive administration of $\mathrm{CP}$ for 5 days did not affect the serum antibody titer to ovalbumin (data not shown).

Effects of drugs on chronic sialoadenitis are shown in Table $3 \mathbf{b}$ and Fig. 3b. IM did not suppress sialoadenitis when estimated with our histological scoring system. Furthermore, major parts of the infiltrating cells in the IM-treated group were not mononuclear but were polymorphonuclear leukocytes in marked contrast to the vehicle-treated group in which mononuclear leukocytes prevailed. Consistent with this result, tissue MPO activity in the IM-treated group was significantly greater than that in the control group. CP suppressed sialoadenitis histologically. Tissue MPO activity in the CP-treated group was as low as that in the control group. A typical light micrograph of chronic sialoadenitis treated with $\mathrm{CP}$ is shown in Fig. 2d.

\section{DISCUSSION}

Several models of experimental allergic sialoadenitis have been investigated to elucidate the pathogenesis of certain inflammatory processes of the salivary glands such as Sjögren's disease. Acute and chronic models of experimental sialoadenitis induced by various immunological methods in rats have been reported by a group of authors in Israel $(1-8)$. Kreisle et al. (9) reported

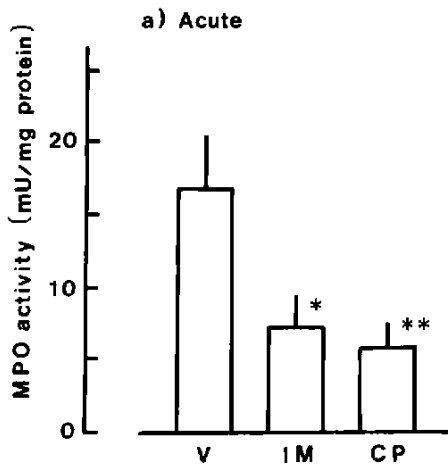

b) Chronic

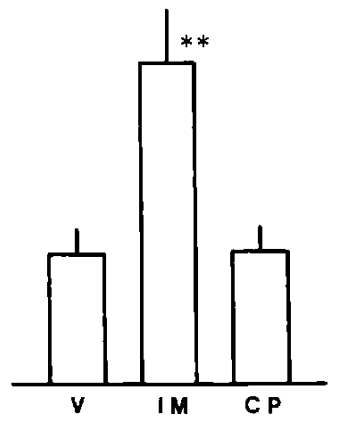

Fig. 3. Effect of drugs on myeloperoxidase activity in the parotid gland of animals with a) acute and b) chronic sialoadenitis. Each column represents the mean $\pm S$.E. of $7-11$ animals. ${ }^{*} \mathrm{P}<0.05$, ${ }^{*} \mathrm{P}<0.01$, significantly different from the vehicle group (Dunnett's test). V: vehicle, IM: indomethacin, CP: cyclophosphamide, details of the drug treatments are described in the Methods.

that in marked contrast to human polymorphonuclear leukocytes, rat polymorphonuclear leukocytes do not exhibit chemotaxis to $\mathrm{LTB}_{4}$ which has been found generally to be a potent mediator in inducing chemotaxis, chemokinesis, degranulation and aggregation for a variety of leukocytes. They pointed out that the lack of chemotactic activity of $\mathbf{L T B}_{\mathbf{4}}$ for rat neutrophils raises questions about the usefulness of rats in the screening of anti-inflammatory agents for potential use in the treatment of human disease. On the contrary, $\mathrm{LTB}_{4}$ causes leukocyte emigration in guinea pigs (12), so we used the guinea pig as an experimental animal in this study.

Autoimmune sialoadenitis was chronically induced in

Table 3. Effects of drugs on acute and chronic sialoadenitis

\begin{tabular}{|c|c|c|c|c|c|c|c|c|c|c|}
\hline \multirow[b]{2}{*}{ Drug } & \multicolumn{5}{|c|}{$\begin{array}{l}\text { Score of } \\
\text { cell infiltration }\end{array}$} & \multicolumn{5}{|c|}{$\begin{array}{l}\text { Score of } \\
\text { tissue destruction }\end{array}$} \\
\hline & 0 & 1 & 2 & 3 & 4 & 0 & 1 & 2 & 3 & 4 \\
\hline \multicolumn{11}{|l|}{ a) Acute sialoadenitis } \\
\hline Vehicle & 0 & 0 & 0 & 1 & 6 & 2 & 5 & 0 & 0 & 0 \\
\hline Indomethacin & 0 & 0 & 2 & 4 & $1^{* *}$ & 6 & 1 & 0 & 0 & $0^{*}$ \\
\hline Cyclophosphamide & 3 & 4 & 0 & 1 & $0^{* *}$ & 8 & 0 & 0 & 0 & $0^{* *}$ \\
\hline \multicolumn{11}{|l|}{ b) Chronic sialoadenitis } \\
\hline Vehicle & 0 & 0 & 0 & 0 & 10 & 0 & 0 & 0 & 5 & 5 \\
\hline Indomethacin & 0 & 0 & 0 & 0 & 8 & 0 & 0 & 0 & 1 & 7 \\
\hline Cyclophosphamide & 0 & 0 & 1 & 8 & $2^{* *}$ & 0 & 1 & 6 & 3 & $1^{* *}$ \\
\hline
\end{tabular}

Values are the incidences of various degrees of sialoadenitis following a) a single and b) multiple intraductal challenges. Histological findings were evaluated according to the criteria and scored as described in the Methods. ${ }^{*} \mathrm{P}<0.05,{ }^{*}{ }^{*} \mathrm{P}<\mathbf{0 . 0 1}$, significantly different from the vehicle group (Mann-Whitney $U$-test). 
guinea pigs by immunizing with a saline extract of the salivary gland combined with different adjuvants, either alone or in combination (13), but a correlation between the incidence and the severity of lesions was rather complicated among the adjuvants. This variation may have resulted from the variation in the amount of antibody production in each animal, and the extract of the salivary gland may essentially not have sufficient antigenicity. So, in this study, we used ovalbumin, one of the most widely used potent antigenic materials, with adjuvant to obtain highly immunized animals. Immunological challenge was made by direct instillation of the antigen into the parotid gland via the parotid duct to induce the antigen-antibody reaction efficiently in the gland and avoid unexpected side effects because other organs were also sensitized with antigen.

A technique for cannulation of the parotid duct of guinea pigs in this study was based on the report on rats by Ulmansky et al. (8). The technique for intraductal cannulation was somewhat difficult, at least in the Wistar and Sprague-Dawley strains that wc tried, because the orifices of the parotid ducts of rats are rather narrow for cannulation. On the other hand, the orifice of the parotid ducts in guinea pigs are wider than those in rats, so it is easy to introduce the catheter into the ducts. This is an additional advantage in using guinea pigs as experimental animals.

In our preparations, acute and chronic sialoadenitis were successfully induced as described in the results. In acute sialoadenitis, mycloperoxidase activity in the parotid gland, which was a marker of accumulation of neutrophils (11), was elevated, but in the chronic stage, it was nearly equal to the control level. This observation is in accord with the histological findings that infiltrating cells in acute and chronic sialoadenitis were mainly polymorphonuclear leukocytes, and mononuclear lcukocytes, respectively.

In the study on drugs, CP suppressed the inflammation both in acute and chronic sialoadenitis. As treatment of CP did not significantly affect the content of anti-ovalbumin antibody in the serum, the anti-inflammatory effect of CP should be a result of reduction of inflammatory cell production and emigration, and/or suppression of their functions. On the other hand, IM inhibited only the acute sialoadenitis induced by a single challenge of antigen, and a defect of the anti-inflammatory effect of IM was observed when multiple immunological challenges were induced. It is unpredictable that polymorphonuclear leukocytes were still dominant in IM-treated chronic sialoadenitis. The detailed mechanism of this phenomenon is unclear, but it seems possible that inhibition of cyclooxygenase by IM may enhance the production of lipoxygenase metabolites by a diversion of the arachidonic acid pathway, and some components of lipoxygenase metabolites such as $\mathrm{LTB}_{4}$ induce emigration of neutrophils. From this point of view, it is of some interest to determine what effects drugs that inhibit $\mathrm{LTB}_{4}$ production or antagonize $\mathrm{LTB}_{4}$ have on these types of allergic inflammations.

In conclusion, our experimental models of acute and chronic sialoadenitis were easy to prepare, and they have a high incidence as compared with similar models in rats reported previously. Since the typical features of inflammatory development from acute to chronic phases were observed in those models, these models may be useful for studying the mechanism of the chronic course in immunologically induced inflammation and the effects of drugs on each phase and chronic course of inflammation.

\section{REFERENCES}

1 Boss, J.H., Rosenmann, E. and Sela, J.: Experimental allergic sialoadenitis. $X$. Chronic destructive parotitis induced in immunized rats by daily intraductal challenges with antigen. J. Oral Pathol. 6, 96-105 (1977)

2 Dishon, T., Sela, Y., Ulmansky, M., Rosenmann, E. and Boss, Y.H.: Experimental allergic sialoadenitis III. Acute parotitis induced by instillation of antiserum to rat plasma into the grandular duct of rats. Experimentia 28, 1360-1361 (1972)

3 Rosenmann, E., Sela, J., Ulmansky, M. and Dishon, T.: Experimental allergic sialoadenitis. II. Induction of acute sialoadenitis in rats locally administered basement membrane antibodies. Oral Surg. 37, 566-575 (1974)

4 Sela, J., Bab, J.A., Rosenmann, E. and Boss, J.H.: Experimental allergic sialoadenitris VIII. Acute parotitis following intraductal instillation of antiserum to salivary antigens in the rat. J. Pathol. 119, 129-133 (1976)

5 Sela, J., Bab, J.A., Dishon, T., Rosenmann, E. and Boss, J.H.: Experimental allergic sialoadenitis. VII. Reactivity of the parotid gland to antigenic challenge in passively immunized rats. J. Oral Pathol. 4, 11-18 (1975)

6 Sela, J., Dishon, T., Rosenmann, E., Ulmansky, M. and Boss, J.H.: Experimental allergic sialoadenitis. V. Comparison of the response of the parotid gland and synovial membranc to multiple antigenic challenges. J. Oral Pathol. 2, 7 15 (1973)

7 Sela, J., Ulmansky, M., Dishon, T., Rosenmann, E. and Boss, J.H.: Experimental allergic sialoadenitis. I. Acute sialoadenitis induced by a local immune reaction. Virchows Arch. Abt. [A] 355, 213-219 (1972)

8 Ulmansky, M., Sela, J., Rosenmann, E. and Boss, J.H.: A technique for the intubation of the parotid duct in rats. Arch. Oral Biol. 17, 609-612 (1971)

9 Kreisle, R.A., Parker, C.W., Griffin, G.L., Senior, R.M. and Stenson, W.F.: Studies of leukotriene $B_{4}$-specific binding and function in rat polymorphonuclear leukocytes: Absence of a chemotactic response. J. Immunol. 134, 3356-3363 (1985) 
10 Orange, R.P. and Moore, E.G.: The effect of thiols on the immunologic release of slow reacting substance of anaphylaxis. II. Other in vitro and in vivo models. J. Immunol. 116, 392 - 397 (1976)

11 Bradley, P.P., Priebat, D.A., Christensen, R.D. and Rothstein, G.: Measurement of cutaneous inflammation: Estimation of neutrophil content with an enzyme marker. J. Invest. Dermatol. 78, 206-209 (1982)
12 Spanda, C.S., Woodward, D.F., Hawley, S.B., Nieves, A.L., Williams, L.S. and Feldmann, B.J.: Synergistic effects of $\mathrm{LTB}_{4}$ and $\mathrm{LTD}_{4}$ on leukocyte emigration into the guinea pig conjunctiva. Am. J. Pathol. 130, 354-368 (1988)

13 Whaley, K. and Macsween, R.N.M.: Experimental induction of immune sialoadenitis in guinea-pigs using different adjuvant. Clin. Exp. Immunol. 17, 681-684 (1974) 